\title{
The value of post-operative antibiotic therapy after laparoscopic appendectomy for complicated acute appendicitis: a prospective, randomized, double-blinded, placebo-controlled phase III study (ABAP study)
}

C. Sabbagh ${ }^{1,2,3}$, N. Siembida ${ }^{1,3}$, H. Dupont ${ }^{2,3,4}$, M. Diouf ${ }^{5}$, J. L. Schmit ${ }^{2,6}$, S. Boddaert ${ }^{7}$ and J. M. Regimbeau ${ }^{1,2,3^{*}}$

\begin{abstract}
Background: Approximately 30\% of appendectomies are for complicated acute appendicitis (CAA). With laparoscopy, the main post-operative complication is deep abscesses (12\% of cases of CAA, versus $4 \%$ for open surgery). A recent cohort study compared short and long courses of postoperative antibiotic therapy in patients with CAA. There was no significant intergroup difference in the post-operative complication rate (12\% of organ/space surgical site infection (SSI)). Moreover, antibiotic therapy is increasingly less indicated for other situations (non-complicated appendicitis, post-operative course of cholecystitis, perianal abscess), calling into question whether post-operative antibiotic therapy is required after laparoscopic appendectomy for CAA.

\footnotetext{
* Correspondence: regimbeau.jean-marc@chu-amiens.fr

'Department of Digestive Surgery, Amiens University Hospital, Amiens University Medical Center, Avenue Laennec, F-80054 Amiens cedex 01, France

${ }^{2}$ Jules Verne University of Picardie, Amiens, France

Full list of author information is available at the end of the article
}

C C The Author(s). 2020 Open Access This article is licensed under a Creative Commons Attribution 4.0 International License, which permits use, sharing, adaptation, distribution and reproduction in any medium or format, as long as you give appropriate credit to the original author(s) and the source, provide a link to the Creative Commons licence, and indicate if changes were made. The images or other third party material in this article are included in the article's Creative Commons licence, unless indicated otherwise in a credit line to the material. If material is not included in the article's Creative Commons licence and your intended use is not permitted by statutory regulation or exceeds the permitted use, you will need to obtain permission directly from the copyright holder. To view a copy of this licence, visit http://creativecommons.org/licenses/by/4.0/ The Creative Commons Public Domain Dedication waiver (http://creativecommons.org/publicdomain/zero/1.0/) applies to the data made available in this article, unless otherwise stated in a credit line to the data. 
(Continued from previous page)

Methods/design: This study is a prospective, multicenter, parallel-group, randomized (1:1), doubleblinded, placebo-controlled, phase III non-inferiority study with blind evaluation of the primary efficacy criterion. The primary objective is to evaluate the impact of the absence of post-operative antibiotic therapy on the organ/space surgical site infection (SSI) rate in patients presenting with CAA (other than in cases of generalized peritonitis). Patients in the experimental group will receive at least one dose of preoperative and perioperative antibiotic therapy $(2 \mathrm{~g}$ ceftriaxone by intravenous injection every $24 \mathrm{~h}$ up to the operation) and metronidazole (500 mg by intravenous injection every $8 \mathrm{~h}$ up to the operation) and, in the post-operative period, a placebo for ceftriaxone $(2 \mathrm{~g} / 24 \mathrm{~h}$ in one intravenous injection) and a placebo for metronidazole $(1500 \mathrm{mg} / 24 \mathrm{~h}$ in three intravenous injections, for 3 days). In the control group, patients will receive at least one dose of preoperative and perioperative antibiotic therapy $(2 \mathrm{~g}$ ceftriaxone by intravenous injection every $24 \mathrm{~h}$ up to the operation) and metronidazole (500 mg by intravenous injection every $8 \mathrm{~h}$ up to the operation) and, in the post-operative period, antibiotic therapy (ceftriaxone $2 \mathrm{~g} / 24 \mathrm{~h}$ and metronidazole $1500 \mathrm{mg} / 24 \mathrm{~h}$ for 3 days). In the event of allergy to ceftriaxone, it will be replaced by levofloxacin $(500 \mathrm{mg} / 24 \mathrm{~h}$ in one intravenous injection, for 3 days). The expected organ space SSI rate is $12 \%$ in the population of patients with CAA operated on by laparoscopy. With a non-inferiority margin of 5\%, a two-sided alpha risk of 5\%, a beta risk of 20\%, and a loss-to-follow-up rate of $10 \%$, the calculated sample size is 1476 included patients, i.e., 738 per group. Due to three interim analyses at $10 \%, 25 \%$, and $50 \%$ of the planned sample size, the total sample size increases to 1494 patients (747 per arm).

Trial registration: Ethical authorization by the Comité de Protection des Personnes and the Agence Nationale de Sécurité du Médicament: ID-RCB 2017-00334-59. Registered on ClinicalTrials.gov (NCT03688295) on 28 September 2018.

Keywords: Complicated appendicitis, Antibiotic therapy

\section{Background}

\section{Appendicitis}

The lifetime risk for acute appendicitis (AA) is 7 to $8 \%$ [1]. Approximately $30 \%$ of these cases are complicated acute appendicitis (CAA; defined as perforated appendicitis, extraluminal fecaliths, an abscess, or local or generalized peritonitis) [2]. Preoperative diagnosis of appendicitis has shifted from suspected appendicitis to proven appendicitis prior to surgery. Preoperative imaging is now the reference for diagnosis and most patients undergo preoperative imaging (ultrasound or computed tomography (CT) scan) [3]. Although appendicitis is a common disease, little is known about its physiology, and the course of the disease (from uncomplicated to complicated appendicitis) is now being questioned.

Complicated and uncomplicated appendicitis may differ in terms of their pathophysiology Complicated appendicitis occurs more frequently in patients with altered inflammatory responses or changes in the colonic microbiome [4]. The results of a recent national cohort study suggest that complicated and uncomplicated appendicitis follow different epidemiological trends over time; the incidence of complicated appendicitis has increased slowly but steadily, whereas non-perforated appendicitis has followed a U-shaped curve. The researchers concluded that complicated and uncomplicated appendicitis were two different diseases, with non-parallel courses and thus non-parallel management [5-7].
Complicated appendicitis is defined as perforated appendicitis, extraluminal fecaliths, an abscess, or local or generalized peritonitis [8]. The definition of localized peritonitis is controversial in terms of the macroscopic aspect of the liquid (from serosity to pus) and the number of quadrants contaminated by pus. It is therefore easier to first define uncomplicated appendicitis (i.e., catarrhal appendicitis without any liquid in the abdomen) and then define complicated appendicitis as any appendicitis that is not uncomplicated. In a recent report on a randomized, controlled trial in children, St Peter et al. defined complicated appendicitis as appendicitis with a hole in the appendix or with fecaliths; they excluded abscesses and local peritonitis from the definition, because the latter conditions were surprisingly associated with a lower rate of post-operative complications than the former (14\% vs 18\%) [8]. Nevertheless, the study of St Peter et al. is the only one to have specified the nature of complicated appendicitis. All other studies have referred to "complicated appendicitis" without providing any details. More recently, a group at Saint-Antoine Hospital developed a predictive score for CAA (without defining CAA). It is based on five factors (a body mass index $(\mathrm{BMI})<28 \mathrm{~kg} / \mathrm{m}^{2}$, a leukocyte count $<15,000 / \mathrm{ml}$, a serum C-reactive protein (CRP) level $<30 \mathrm{mg} / \mathrm{l}$, an appendix diameter of $10 \mathrm{~mm}$ or less, and the absence of radiological signs of perforation). The likelihood of CAA 
(ranging from $0 \%$ with a score of 5 to $100 \%$ with a score of 0 ) can therefore be used to preoperatively identify patients with CAA [9]. The highest risk for CAA was associated with a Saint-Antoine score $\leq 3$. In the present study, we define cases of CAA as patients with a preoperative Saint-Antoine score $\leq 3$ that are perioperatively confirmed by the presence of a perforated appendix, extraluminal fecaliths, abscesses, and/or localized peritonitis (pus in one or two abdominal quadrants), according to a recent study of our group [10]. In this study, we found a concordance between surgeons in $85 \%$ of cases for the definition of a CAA and the type of CAA (localized or generalized peritonitis) and two quadrants was the best cut-off between localized and generalized peritonitis by receiver operating characteristic (ROC) curve analysis [10]. We have used this definition (two or less quadrants with pus) to define localized peritonitis.

In conclusion, appendicitis is a frequently occurring disease and the Saint-Antoine score (externally validated by our group $[7,11]$ ) helps to identify patients with CAA and thus select patients for the present study.

\section{Complicated appendicitis}

The treatment of complicated appendicitis always includes appendectomy and aspiration of the pus. Exclusive antibiotic therapy is contraindicated.

One of the antibiotic therapies recommended during the preoperative period by both the Société Française d'Anesthésie Réanimation (SFAR) and the Infectious Diseases Society of America (IDSA) is a combination of ceftriaxone and metronidazole ( $2 \mathrm{~g}$ ceftriaxone by intravenous injection every $24 \mathrm{~h}$ up to the operation and 500 mg metronidazole by intravenous injection every $8 \mathrm{~h}$ up to the operation), with at least one injection before the operation $[12,13]$. The IDSA also recommends performing routine aerobic culture tests during the operation to ensure that the antibiotic therapy can be modified in the event of post-operative complications [14].

We have few data (and none from published trials) on the post-operative period. However, available data suggest that post-operative antibiotics are of no value. A Cochrane meta-analysis published in 2005 suggested that the post-operative infection rate was lower in patients who received antibiotic therapy after surgery for AA (odds ratio (OR) $[95 \% \mathrm{CI}]=0.35$ [0.13-0.91]; $p=$ 0.03 ). When only cases of CAA were considered, the difference was no longer significant $(\mathrm{OR}[95 \% \mathrm{CI}]=0.54$ $[0.12-2.43] ; p=0.4)$ [15]. However, all the studies included in the Cochrane meta-analysis are more than 20 years old (i.e., published before 1995) and featured laparotomy appendectomy. Laparoscopy was never mentioned and these studies thus no longer provide valid data to address this question (given that $52 \%$ of appendectomies are now performed by laparoscopy) [2].
A recent cohort study compared a short (3-day) course of antibiotics with a long course (at least 5 days) for patients with CAA who underwent a laparoscopic or open appendectomy. There was no significant intergroup difference in the overall post-operative complication rate $(\mathrm{OR}[95 \% \mathrm{CI}]=1.7[0.72-4.01] ; p=0.2)$ or the rate of developing an intra-abdominal abscess $(\mathrm{OR}[95 \% \mathrm{CI}]=1.77$ [0.68-4.58]; $p=0.2)$ [16]. The same authors published a national prospective observational study comparing a 3day course of antibiotics instead of 5-day course in 2016. They found no difference in the rate of postoperative complications, especially for the rate of developing a postoperative abscess (OR 0.89; 95\% CI $0.34-2.35 ; p=$ $0.81)$. In this study, the rate of developing a postoperative abscess was $12 \%$ [17]. This raises the question of whether post-operative antibiotic therapy is required after laparoscopic appendectomy for CAA. These data are true for all types of complicated appendicitis, except generalized peritonitis, which constitutes a particular group (classified as a high-risk, community-acquired infection by the SFAR). The use of post-operative antibiotic therapy in generalized peritonitis is based essentially on expert consensus, as there are no specific studies supporting this approach. Nevertheless, a 5-day course of antibiotic treatment is required, making generalized peritonitis a special entity and explaining why we excluded this category of patients from the present study [12].

In conclusion, the value of post-operative antibiotic therapy for complicated appendicitis is open to question (except in cases of generalized peritonitis).

\section{Choice of evaluation criteria}

The main post-operative complication for patients with complicated appendicitis after laparoscopy is an organ/ space surgical site infection (SSI). In the literature, the incidence of organ/space SSIs for complicated appendicitis (except for generalized peritonitis), i.e., perforated appendicitis, fecaliths outside the appendix, abscess, and localized peritonitis, ranges from 4 to $19 \%$. Most data come from studies that compared open and laparoscopic appendectomy and that did not give details of the postoperative antibiotic therapy. In 1996, Frazee et al. reported an organ/space SSI rate of $7 \%$ for patients who underwent laparoscopy, without providing any details of the antibiotic therapy [18]. In 2004, Ball et al. reported an organ/space SSI rate of $4 \%$ for patients receiving post-operative ciprofloxacin-flagyl for 7 days after discharge [19]. In 2007, Pokala et al. reported a rate of $14 \%$ but did not provide details of the post-operative antibiotic therapy [20]. In 2010, the national cohort study of Tuggle et al. from the USA reported an organ/space SSI rate of $7 \%$ in the subgroup of CAA patients who underwent laparoscopy [21]. In 2014, a cohort study of 1143 patients compared 3 with 5 days of post-operative 
antibiotic therapy and found an organ/space SSI rate of $7.9 \%$ [16]. The patients received preoperative intravenous antibiotic therapy (cefozopran hydrochloride, $1 \mathrm{~g}$ every 12 $\mathrm{h}$ ), which was continued into the post-operative period until the inflammatory response abated (based on clinical and laboratory findings, such as fever, pain, bowel movement, oral intake, white blood cell count, and CRP levels). In 2016, Van Rossem et al. reported an organ/space SSI rate of $12 \%$ in a national prospective cohort study on patients with localized peritonitis who underwent laparoscopy [17]. We chose $12 \%$ as a reference value for patients on post-operative antibiotics to avoid underestimation of the incidence of organ/space SSIs.

In conclusion, the organ/space (deep) SSI rate is the best criterion for evaluating post-operative complications in patients who undergo laparoscopy.

\section{Choice of antibiotic therapy}

The choice of the antibiotic therapy is based on the SFAR and IDSA guidelines adapted to match the bacteriological epidemiology of peritonitis in France. Among the validated therapies, the choice of that used in the protocol was validated by a professor of infectious disease (JLS) and a professor of critical care medicine (HD), who both also participated in writing the SFAR guidelines [12].

In the literature, first-line empirical therapy for peritonitis with no signs of severity must target Enterobacteriaceae and anaerobic bacteria. In France, $>75 \%$ of the Enterobacteriaceae isolated from adult cases of community-acquired peritonitis are susceptible to amoxicillin/clavulanic acid (AMC) [22]. Most cases (90 to 100\%) of AMC-resistant Enterobacteriaceae are still susceptible to aminoglycosides and thirdgeneration cephalosporins [22]. In France, the prevalence of extended-spectrum beta-lactamase-producing Enterobacteriaceae in samples from community-acquired peritonitis in adults is low, and these organisms do not need to be considered in empirical antibiotic therapy (other than in particular local or regional epidemiological contexts). Fluoroquinolones alone are not recommended as a first-line therapy due to a higher rate of resistance [12, 22].

In conclusion, the chosen post-operative antibiotic therapy is ceftriaxone, $2 \mathrm{~g} / 24 \mathrm{~h}$ in one intravenous injection, and metronidazole, $1500 \mathrm{mg} / 24 \mathrm{~h}$ in three intravenous injections for 3 days. In the event of allergy to ceftriaxone, it will be replaced by levofloxacin $(500 \mathrm{mg} /$ $24 \mathrm{~h}$ in one intravenous injection, for 3 days).

The aim of this study is to evaluate the use of postoperative antibiotic therapy in complicated appendicitis, with the exception of general peritonitis.

\section{Methods/design}

We hypothesize that post-operative antibiotic therapy is of no value after appendectomy for complicated appendicitis. We expect to observe non-inferiority of the absence of post-operative antibiotic therapy in terms of the organ/space SSI rate in patients presenting with CAA.

\section{Trial design}

This is a prospective, investigational, comparative, double blinded, placebo-controlled, non-inferiority, phase III clinical trial with two parallel groups (randomized 1:1) and a blind analysis of the primary endpoint.

\section{Inclusion criteria}

The ABAP study will include patients with 1) CAA suspected preoperatively and confirmed perioperatively by the presence of a perforated appendix, extraluminal fecaliths, abscesses, and/or localized peritonitis (pus in one or two abdominal quadrants). The time from the onset of symptoms to presentation is not considered. The method of imaging is not imposed (ultrasound or CT scan). There is no official definition of localized CAA. Thus, a training video, based on a previous publication from our group, will be shown at the screening visit to ensure that all investigators have the good definition of localized CAA. The study will also include patients who 2) undergo a laparoscopic appendectomy, 3) are aged $\geq$ 18 years, and 4) provide a signed written consent form.

\section{Exclusion criteria}

The specific exclusion criteria are detailed in Table 1.

The other exclusion criteria are related to the research and include: 1) pregnancy or breastfeeding, 2) patients under guardianship, 3) patients unable to give their informed consent, and 4) patients lacking social security coverage.

\section{Endpoints of the trial Primary outcome}

The primary outcome will be the proportion of patients with organ/space SSIs by postoperative day (POD) 30. Organ/space SSIs are officially defined by the CDC [23] as infections that occur within 30 days of surgery AND appear to be related to the surgery AND affect the organ or the cavity around the surgical site (i.e. any anatomical structure-other than the incision-that is opened or handled during surgery) AND for which at least one of the following signs is observed: pus coming from a drain placed in the organ or cavity, bacteria isolated from a liquid or tissue sample collected aseptically from the organ or cavity, and an abscess or other obvious sign of infection of the organ or cavity found by macroscopic examination during subsequent surgery or in a radiological or histopathological examination. Infection of the organ or cavity is diagnosed by the surgeon (or the physician attending to the patient). In the protocol, the SSI will be confirmed on a CT scan by the presence of an 
Table 1 Exclusion criteria

\begin{tabular}{|c|c|}
\hline \multicolumn{2}{|l|}{ Preoperative exclusion criteria } \\
\hline Related to the diagnosis & $\begin{array}{l}\text { 1) Crohn's disease, ulcerative colitis, } \\
\text { treatment with an immunosuppressive } \\
\text { therapy } \\
\text { 2) Patients who received an adaptive dose } \\
\text { of levofloxacin } 250 \mathrm{mg} / 24 \mathrm{~h} \text { instead of } 500 \\
\text { mg/24 h, preoperatively or perioperatively } \\
\text { (notably for patients with creatinine } \\
\text { clearance } \leq 50 \mathrm{ml} / \mathrm{min} \text { ), or who have an } \\
\text { allergy to metronidazole or one of the } \\
\text { excipients and/or who have a contra- } \\
\text { indication for the use of ceftriaxone (hyper- } \\
\text { sensitivity to the active substance, to an- } \\
\text { other cephalosporin, to the excipient of the } \\
\text { used drug) or who have a history of severe } \\
\text { hypersensitivity (such as anaphylactic } \\
\text { shock) or hypersensitivity to another anti- } \\
\text { biotic of the beta-lactam family (penicillin, } \\
\text { monobactam, carbapenems) or who have a } \\
\text { contraindication for the use of levofloxacin, } \\
\text { hypersensitivity to levofloxacin, another } \\
\text { quinolone, or the excipient of one of the } \\
\text { used drugs, hypersensitivity to levofloxacin } \\
\text { or any other quinolone or any excipient, a } \\
\text { history of epilepsy, or a history of tendinitis } \\
\text { when injected with fluoroquinolones }\end{array}$ \\
\hline $\begin{array}{l}\text { Related to the severity } \\
\text { of the appendicitis }\end{array}$ & $\begin{array}{l}\text { 1) Severe sepsis, septic shock, or } \\
\text { generalized peritonitis }\end{array}$ \\
\hline $\begin{array}{l}\text { Related to the } \\
\text { treatment }\end{array}$ & $\begin{array}{l}\text { 1) A decision to perform open } \\
\text { appendectomy or a conversion to open } \\
\text { surgery }\end{array}$ \\
\hline \multicolumn{2}{|l|}{ Perioperative exclusion criteria } \\
\hline $\begin{array}{l}\text { Related to the severity } \\
\text { of the appendicitis }\end{array}$ & $\begin{array}{l}\text { 1) Non-complicated forms (catarrhal appen- } \\
\text { dicitis or the absence of extraluminal feca- } \\
\text { liths, abscess, or peritonitis) } \\
\text { 2) Generalized purulent or stercoral } \\
\text { peritonitis (the presence of pus or feces in } \\
\text { more than two quadrants of the abdomen) }\end{array}$ \\
\hline
\end{tabular}

${ }^{a}$ Severe sepsis is defined as sepsis plus sepsis-induced organ dysfunction or tissue hypoperfusion. Septic shock is defined as persistent sepsis-induced hypotension, despite adequate fluid resuscitation

organ/space abscess (defined as an enwalled fluid-filled cavity in which the fluid contains gases) [24], which will be treated with antibiotics (either alone or in combination with radiological or surgical drainage, depending on the clinician's decision).

The investigators evaluating the primary endpoint will be blinded to the treatment group.

\section{Secondary outcomes}

The secondary outcomes include three types: patient related, infection related, and surgery related.

The patient-related outcomes will include their quality of life prior to surgery, on discharge, and on POD 30, using the EuroQol 5D and SF36 questionnaires.

The principal infection-related outcome will be the proportion of patients with superficial SSIs, defined as infections that occur within 30 days of the intervention and affect the skin and subcutaneous tissues and for which at least one of the following signs is observed: pus coming from the superficial part of the incision, bacteria isolated from a liquid or tissue sample collected aseptically from the superficial part of the incision, a sign of infection (pain, tenderness, redness, burning, etc.) associated with deliberate opening of the superficial part of the incision by the surgeon (except if the culture is negative). Infection of the superficial part of the incision is diagnosed by the surgeon (or the physician attending to the patient). The definitions are based on that published by the CDC. Additional infection-related outcomes include the post-operative infection rates by POD 30, including SSIs and distant infections, the number of antibiotic-free days between randomization and POD 30, a description of the microbial flora, as found in the antibiogram of the perioperative sample that is collected in all cases, and the balance between antibiotic therapy and microbial resistance. The antibiotic treatment will be considered adequate if no bacteria are found in the perioperative sample or if all of the detected bacteria are sensitive to the administered antibiotic therapy. The antibiotic treatment will be considered inadequate if the perioperative sample is positive for resistant bacteria.

Surgery-related outcomes will include morbidity and mortality according to the Dindo-Clavien classification [25] and the CCI [26]; length of stay (LOS), defined as the number of days of hospitalization between surgery and discharge; and rehospitalization rate, defined as rehospitalization during the study period.

\section{Treatment administered}

After randomization, patients in the treatment group will receive at least one dose of preoperative and perioperative antibiotic therapy (ceftriaxone, $2 \mathrm{~g}$ via intravenous injection every $24 \mathrm{~h}$ up to the operation, and metronidazole, $500 \mathrm{mg}$ via intravenous injection every 8 $\mathrm{h}$ up to the operation). In the event of an allergy to ceftriaxone, it will be replaced by levofloxacin $(500 \mathrm{mg} / 24 \mathrm{~h}$ in one intravenous injection up to the operation). The perioperative period will start at the beginning of anesthesia and finish at the end of anesthesia. In the post-operative period, patients will receive a placebo for ceftriaxone, $2 \mathrm{~g} / 24 \mathrm{~h}$ in one intravenous injection (or a placebo for levofloxacin $500 \mathrm{mg} / 24 \mathrm{~h}$ in one intravenous injection for 3 days, in case of allergy to ceftriaxone), and a placebo for metronidazole, $1500 \mathrm{mg} / 24 \mathrm{~h}$ in three intravenous injections, for 3 days.

Ceftriaxone is a third-generation cephalosporin with broad-spectrum Gram-negative activity. It has low efficacy against Gram-positive organisms but high efficacy against resistant organisms. Furthermore, it is highly stable in the presence of beta-lactamases (penicillinase and cephalosporinase) secreted by Gram-negative and Gram-positive bacteria. The compound's bactericidal activity results from inhibiting the synthesis of peptidoglycan (a major 
structural component of the bacterial cell wall) through binding to one or more penicillin-binding proteins. The bacteria eventually lyse because the activity of cell-wall autolytic enzymes continues while cell-wall assembly is arrested. Ceftriaxone is metabolized by the liver. Metronidazole is an anti-infectious nitroimidazole derivative with the highest activity against strict anaerobes.

After randomization, patients in the control group will receive at least one dose of preoperative and perioperative antibiotic therapy (ceftriaxone $2 \mathrm{~g}$ by intravenous injection every $24 \mathrm{~h}$ up to the operation) and metronidazole $(500 \mathrm{mg}$ by intravenous injection every 8 $\mathrm{h}$ up to the operation). In the event of an allergy to ceftriaxone, it will be replaced by levofloxacin $(500 \mathrm{mg} / 24 \mathrm{~h}$ in one intravenous injection up to the operation). In the post-operative period, antibiotic therapy (ceftriaxone $2 \mathrm{~g} /$ $24 \mathrm{~h}$ and metronidazole $1500 \mathrm{mg} / 24 \mathrm{~h}$ ) will be continued for 3 days. In the event of allergy to ceftriaxone, it will be replaced by levofloxacin $(500 \mathrm{mg} / 24 \mathrm{~h}$ in one intravenous injection, for 3 days). The antibiotic therapy in the control group is that recommended by the Sociéte Francaise d'Anesthésie Réanimation (SFAR) and the American IDSA guidelines.

\section{Data collected and follow-up}

The screening visit is conducted by the investigating physician. It will take place on the day of the inclusion visit. Before the initiation of any study-related examinations, the investigator will obtain the participant's written, informed consent. To assess generalizability, all patients fulfilling the eligibility criteria in each center will be recorded in a table.

The screening visit will include a physical examination, including cardiac blood flow, body temperature, and pain evaluation, and a biological examination, including a blood ion profile, and ASAT, ALAT, total bilirubin, indirect bilirubin, alkaline phosphatase, GGT, amylase, lipase, CRP, hCG (if applicable), procalcitonin levels, and leukocyte count.

\section{Obtaining consent}

At the screening visit, the investigating physician informs the patient about the study and answers any questions the patient may have regarding the study's objective, nature, constraints, anticipated risks, expected benefits, the placebo, and blinding. The physician also explains the patient's rights in the context of interventional research involving human subjects and checks the eligibility criteria. A copy of the study information sheet and the consent form are then given to the participant by the investigating physician.

After this information session, the participant has a period of time to consider his/her decision. The investigating physician is responsible for obtaining written, informed consent from the participant. The consent form must be signed before randomization.

If the patient agrees to participate in the study, he/she and the investigator write their names and forenames clearly on the consent form and then date and sign it. Copies of the study information sheet and the consent form are then given to the participant and the original kept by the investigating physician in a closed room, as recommended by national legislation. At the end of the inclusion period (or at the end of the study at the latest), a copy of each consent form is sent to the sponsor or his/her representative via the procedure to be communicated to the investigators in due course.

\section{Inclusion visit}

The inclusion visit (which is the same as the screening visit) will include a physical examination, including cardiac blood flow, body temperature, and pain evaluation; a laboratory test battery (blood ion profile, ASAT, ALAT, total bilirubin, indirect bilirubin, alkaline phosphatase, GGT, amylase, lipase, CRP, hCG (if applicable), procalcitonin levels, and leukocyte count).

The laparoscopic appendectomy will then be performed, regardless of the hour or day, and the randomization performed after the appendectomy.

\section{Follow-up visits}

During hospitalization, the patient will be examined twice a day by the attending medical staff. A blood test will be performed on day one (a complete blood count, platelet count, C-reactive protein, and procalcitonin levels; Table 2, Spirit figure).

Depending on the clinical situation and the suspected presence of infection, several scenarios are possible. Patients randomized into the antibiotic group can potentially be discharged by the surgeon after completion of the intravenous treatment on POD 4 if there is no postoperative infection. In such an event, the antibiogram will not be inspected by the surgical team. If the patient has a temperature of more than $38.5^{\circ} \mathrm{C}$ (suggesting the presence of a post-operative infection), appropriate additional examinations and an antibiogram will be obtained. If a postoperative infection is confirmed and the antibiogram results are available, the antibiotic treatment will be modified. If a post-operative infection is not confirmed, other appropriate treatment will be provided (Fig. 1).

Patients randomized into the non-antibiotic group can potentially be discharged by the surgeon after completion of the intravenous placebo on POD 4 if there is no post-operative infection. If the patient has a temperature of more than $38.5^{\circ} \mathrm{C}$ (suggesting the presence of a postoperative infection), appropriate additional examinations and an antibiogram will be obtained. If a post-operative infection is confirmed, an appropriate antibiotic 
Table 2 Follow-up visits (Spirit figure)

\begin{tabular}{|c|c|c|c|c|c|c|c|c|}
\hline & $\begin{array}{l}\text { Screening } \\
\text { visit } \\
\text { D-1 or } \\
\text { D0 }\end{array}$ & $\begin{array}{l}\text { Inclusion } \\
\text { D-1 or } \\
\text { D0 }\end{array}$ & $\begin{array}{l}\text { Preoperative } \\
\text { period } \\
\text { D-1 or D0 }\end{array}$ & $\begin{array}{l}\text { Perioperative } \\
\text { period }\end{array}$ & $\begin{array}{l}\text { Post-operative } \\
\text { period } \\
\text { D1-D3 }\end{array}$ & $\begin{array}{l}\text { Post-operative } \\
\text { FU call } \\
\text { D8 post- } \\
\text { surgery }\end{array}$ & $\begin{array}{l}\text { Post-operative } \\
\text { FU visit } \\
\text { D15 } \pm 7 \text { post- } \\
\text { surgery }\end{array}$ & $\begin{array}{l}\text { Post-operative } \\
\text { FU visit } \\
\text { D30 } \pm 7 \text { post- } \\
\text { surgery }\end{array}$ \\
\hline Check on eligibility & $\checkmark$ & $\checkmark$ & & & & & & \\
\hline Informed consent & & $\checkmark$ & & & & & & \\
\hline Clinical examination & & $\checkmark$ & $\checkmark$ & $\checkmark$ & & & & $\checkmark$ \\
\hline Biological examination & & $\checkmark$ & $\checkmark$ & $\checkmark$ & & $\boldsymbol{V}^{\mathrm{a}}$ & & \\
\hline $\begin{array}{l}\text { B-hCG test (women of } \\
\text { child-bearing age) }\end{array}$ & & $\checkmark$ & & & & & & \\
\hline Search for AEs & & $\checkmark$ & $\checkmark$ & $\checkmark$ & & & & $\checkmark$ \\
\hline $\begin{array}{l}\text { Surgery (laparoscopic } \\
\text { appendectomy) }\end{array}$ & & & & $\checkmark$ & & & & \\
\hline Randomization & & & & $\checkmark$ & & & & \\
\hline $\begin{array}{l}\text { Systematic perioperative } \\
\text { sample }\end{array}$ & & & & $\checkmark$ & & & & \\
\hline $\begin{array}{l}\text { Post-operative antibiotics } \\
\text { for } 3 \text { days }\end{array}$ & & & & & $\checkmark$ & & & \\
\hline Daily follow-up visits & & & & $\checkmark$ & & & & \\
\hline $\begin{array}{l}\text { Post-surgery follow-up } \\
\text { surgeon }\end{array}$ & & & & & & $\checkmark$ & $\checkmark$ & $\checkmark$ \\
\hline
\end{tabular}

treatment will be administered. If a post-operative infection is not confirmed, other appropriate treatment will be provided.

At the moment of discharge, patients will leave with a letter describing all the signs to monitor that should elicit the patient to seek medical care. $\mathrm{He} / \mathrm{she}$ will be called by the investigating site on POD 8 to diagnose any sign of complications. Patients will be asked whether they had fever or abdominal pain and be reminded of the phone number of the hospital digestive surgery unit, as given in the discharge letter (available $24 \mathrm{~h}$ a day). At the postoperative follow-up visits, the investigator will check for post-operative complications. The first visit will take place 15 days after the patient's surgery and will include a blood test (a complete blood count, platelet count, C-reactive protein, and procalcitonin levels). The second visit will take place 28 days after the patient's surgery. During the follow-up visit, the investigator will check on the occurrence of an adverse event and (if applicable) the management of this event (hospitalization, antibiotics, radiological, or surgical drainage, etc.). The primary endpoint will be evaluated at this time.

\section{End of follow-up visit}

There will be two post-operative visits, on POD 15 and one month ( \pm 1 week) after the patient's discharge. This visit will be performed by the investigators (and not by the patient's general practitioner) for all included patients. Patients not seen at POD 15 and/or one month will be invited to visit the hospital. The patient's general practitioner (who will have received a letter emphasizing the importance of the primary endpoint) will also be contacted before the patient is considered to have been lost to follow-up.

All data will be anonymized.

\section{Cessation rules}

All patients will be free to withdraw their consent and ask to be withdrawn from the study at any time and for any reason. In the event of premature withdrawal, the investigating physician must specify the reason as fully as possible.

The investigating physician will be able to withdraw a patient for any reason that might harm the patient (especially the presence of an adverse event).

The study may be stopped in the event of unexpected serious adverse events or new information suggesting that the study's objectives will not be reached, as decided by the sponsor. A data safety monitoring board (DSMB) has been nominated (including a biostatistician, a surgeon, an infectious disease specialist, and an anesthesiologist). There will be a meeting after the first ten inclusions (in case of an adverse event), every 100 inclusions, and at the interim analysis. The DSMB has the power to stop the study.

\section{Randomization}

An interactive web response system will be used to randomize patients using a randomization list with 


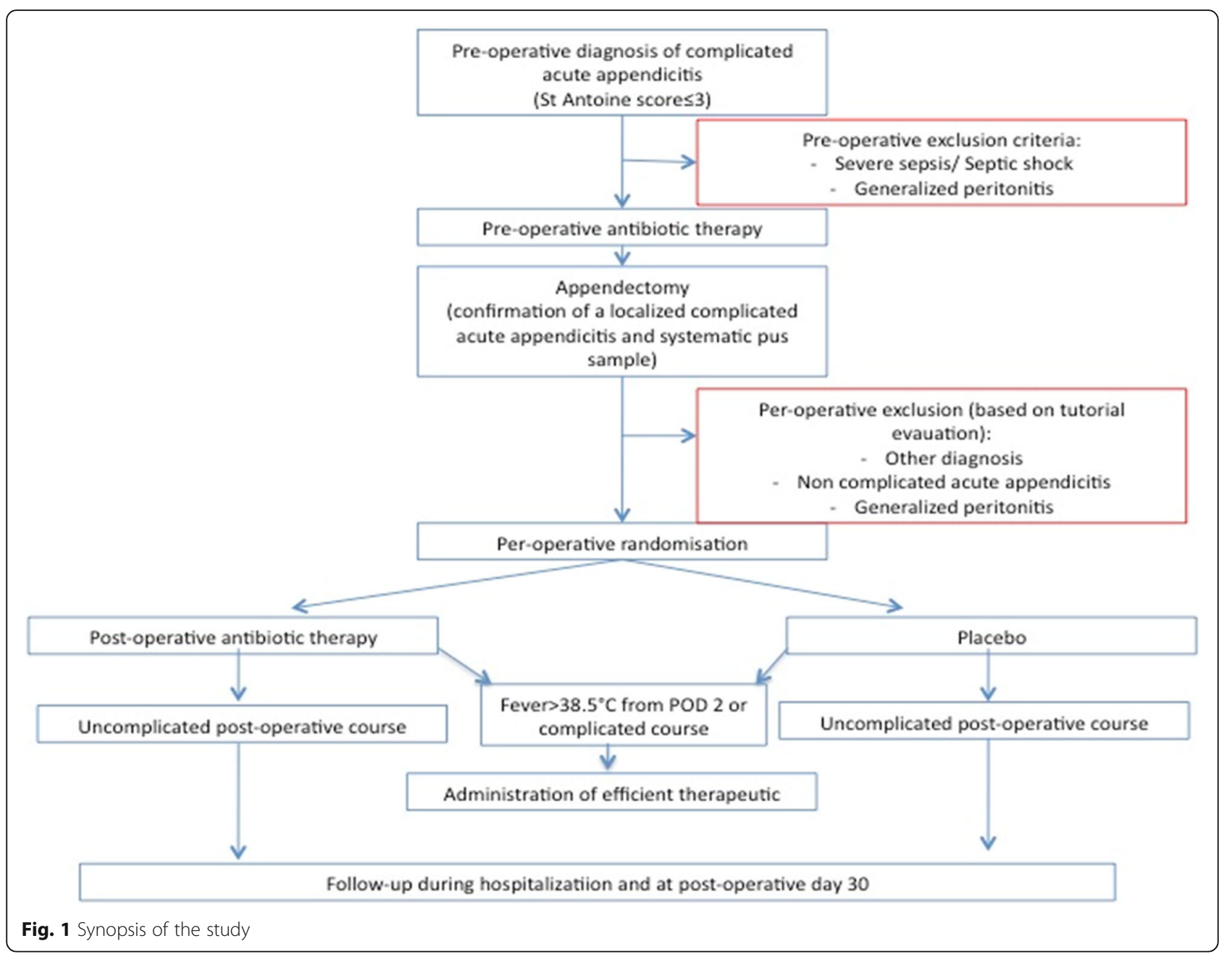

blocks of equal size (with the same number of randomized patients in each group, i.e., antibiotics vs no antibiotics) and stratified by center.

At the end of the surgery, investigators will check the inclusion and non-inclusion criteria. If the patient meets all of the inclusion criteria and none of the noninclusion criteria, the investigators will $\log$ him/her into the electronic case report form and request that a treatment number be allocated to the patient.

The sequence of the study treatments (preoperative and perioperative antibiotic therapy, laparoscopic appendectomy, with or without post-operative antibiotic therapy) will be generated by a data manager using a computer program. The allocation of patients to the different study groups will involve the use of a secure, independent computer to ensure that the investigator cannot interfere with the results of this procedure. Randomization (1:1) will be stratified by center.

Randomization will be performed by an identified investigator. At the end of the surgery, the investigator will log onto the study web site (https://recherche-clinique.chu- amiens.fr/csonline/) using his/her personal username and password. The patient will be registered online and a participant number will be allocated. If the patient satisfies the inclusion/exclusion criteria and stratification criteria, he/she will be randomized, and the investigator will gain access to the treatment number allocated to the patient.

\section{Blinding method}

This will be a double-blind study. In the post-operative period, patients will receive either the antibiotic therapy (ceftriaxone-metronidazole or levofloxacin-metronidazole) or the placebo. Both will be injected intravenously for 3 days. The placebo will be formulated in the same format as the antibiotics. The investigators evaluating the primary endpoint will be blinded to the treatment group, as well as the included patients. The nurses who perform the injection will not be blinded. The vigilance unit must have a copy of the randomization list or a set of envelopes for unblinding.

Unblinding will be performed by the vigilance unit if the occurrence of an unexpected serious adverse effect 
(SAE) is suspected before declaration to the competent health authorities and annually when annual safety reports are drafted.

\section{Participating centers}

The patients will be recruited with help from the Federation de Recherche EN CHirurgie (FRENCH) centers that have already participated in another randomized control trial funded by the PHRC (the ABCAL trial, in 2009) [27].

\section{Statistical methods \\ Sample size}

The patients will be randomized into two groups, 1 and 2. Group 1 will not receive post-operative antibiotic therapy (the experimental group) and group 2 will receive post-operative antibiotic therapy (the control group). The groups will be compared in terms of the primary endpoint (i.e., the incidence of organ/space SSIs). The study is based on a non-inferiority analysis.

The hypothesis of the study is that the absence of post-operative antibiotic therapy is at least as good as or similar to the presence of post-operative antibiotic therapy. Furthermore, we assume that the incidence of organ/space SSIs in the reference group is $12 \%$.

The expected organ space SSI rate of $12 \%$ in the population of patients with CAA who undergo laparoscopy is based on the publication by Van Rossem et al. [17]. With a non-inferiority margin of 5\%, a two-sided alpha risk of $5 \%$, a beta risk of $20 \%$, and a loss-to-follow-up rate of $10 \%$, the calculated sample size is 1476 included patients, i.e., 738 per group. Due to three interim analyses at $10 \%, 25 \%$, and $50 \%$ of the planned sample size, the total sample size increases to 1494 patients (747 per arm). The sample was calculated using the equation on page 290 of the book by S Piantadosi (Clinical trials: $A$ Methodological Perspective (2nd edition), John Wiley and Sons, Hoboken, 2005).

\section{Statistical methods}

Qualitative variables will be presented as numbers (percentages) and compared using a chi-squared test with Yates' correction or (if applicable) Fisher's test. Quantitative variables will be presented as the means \pm standard deviation or medians (interquartile range) and compared using Student's $t$-test or a Wilcoxon signed-rank test, as appropriate. Kaplan-Meier curves for the time to event will be built and compared using a log-rank test.

A detailed statistical analysis plan will be defined and validated by the study's scientific advisory board. Any modifications must be made before unblinding of the database and must be validated by the scientific advisory board.
Analysis of the primary endpoint Non-inferiority will be established if the upper limit of the two-sided 95\% confidence interval of the difference in the proportion of infections between the two groups (placebo arm - antibiotic arm) is lower than the non-inferiority margin (5\%). An intention-to-treat analysis will be followed by a per-protocol analysis. A multiple imputation analysis will be performed if more than $5 \%$ of the data are missing for the primary endpoint.

Analysis of secondary endpoints The patient-related endpoint, consisting of quality of life prior to surgery, on discharge, and on POD 30 after surgery, will be assessed in a mixed model analysis of variance with a Bonferonni-Holm closed testing procedure for post hoc analyses.

In terms of the infection-related endpoints, the proportion of patients with superficial SSIs will be assessed using a chi-squared test or Fisher's test. The postoperative infection rates by POD 30, including SSIs and remote infections, will also be assessed using a chisquared test or Fisher's test. The number of antibioticfree days between randomization and POD 30 will be assessed using Student's $t$-test or a Wilcoxon test. The microbial flora will be assessed using a chi-squared test or Fisher's test. The proportion of patients with adequate antibiotic treatment will also be assessed using a chisquared test or Fisher's test.

In terms of the surgery-related endpoints, morbidity and mortality (according to the Dindo-Clavien classification) will be assessed using a Wilcoxon test, LOS will be assessed using a chi-squared test or Fisher's test, and the rehospitalization rate will be assessed using a chisquared test or Fisher's test.

Statistical analysis will be performed using $\mathrm{SAS}^{\circ}$ software (version 9.4, SAS Institute Inc., Cary, NC, USA).

\section{Ethical considerations}

The sponsor and the investigators undertake to ensure that the study is performed according to the French Public Health act 2004-806, dated August 9 2004, Good Clinical Practices (ICH version 4, dated May 1 1996, and the decision dated November 24 2006), and the Declaration of Helsinki (a complete version of which may be found at: http://www.wma.net). Ethical authorization has been given by the Comité de protection des personnes and Agence nationale de sécurité du médicament: IDRCB 2017-00334-59.

The study will be conducted according to the present protocol. With the exception of emergency situations requiring the implementation of specific therapeutic procedures, the investigators undertake to comply with every aspect of the protocol, particularly those concerning obtaining the patient's informed consent and the 
notification and follow-up of serious adverse events (surgical site infection, pneumonia, fever $>38.5^{\circ} \mathrm{C}$, postoperative hemorrhage, venous thromboembolism, pulmonary embolism, myocardial infarction, or stroke).

In accordance with the provisions of Article L1121-10 of the French Public Health Code, the study sponsor (Amiens University Hospital) has taken out a civil liability insurance policy with Société Hospitalière d'Assurance Mutuelles (18 Rue Edouard Rochet, F-69372 Lyon cedex 08, France; policy number 147731 RC RECH. BIOMEDICALES).

Data recorded during this study will undergo automated processing by the Amiens University Hospital Biostatistics Unit, in accordance with the French Data Protection Act 78-17, dated January 6, 1978, and the French Data Protection Act 2004-801, dated August 6, 2004.

This study falls within the scope of the "Reference Methodology" (Méthodologie de référence, MR-001) described in article 54, paragraph 5 of the French Data Protection Act 78-17, dated January 6, 1978 (amended). This modification was approved by the decision dated January 5, 2006. Amiens University Hospital has signed to comply with this Reference Methodology.

In accordance with Article L1121.15 of the French Public Health Code, the present study is registered in the European EudraCT database under No. 2017-000334-59. This study was also registered on the ClinicalTrials.gov website (http://clinicaltrials.gov/; NCT03688295) on September 28, 2018.

The biological sample collection performed in the context of this research was registered with the ANSM at the same time as the application for a clinical trial authorization. After termination of the study, storage of the biological sample collection will be registered with the French Ministry of Research and the Regional Health Agency (Agence Régionale de Santé). If the purpose of the research changes, approval from the CPP (IEC/IRB) will be requested.

\section{Discussion}

In 2014, the world Health Organization published a report on the escalating global incidence of multidrug resistance caused by antibiotic overuse, which has become a significant threat to public health worldwide [28]. For example, antibiotic use is a risk factor for Clostridium difficile infections. In addition, prolonged antibiotic therapy after surgery can cause nausea, allergic reactions, and digestive complaints. Extended intravenous antibiotic prophylaxis leads to the prolongation of hospital stays and increased costs. There has thus recently been a tendency to minimize the use of postoperative antibiotics for uncomplicated appendicitis and anorectal abscesses $[28,29]$.
In this field, complicated appendicitis is a frequently occurring disease and accounts for $30 \%$ of all appendicitis cases. Thus, there is a real need to address this question. In this context, the first point to resolve was the definition of CAA, for which there are few data. St Peter et al. defined complicated appendicitis as appendicitis with a hole in the appendix or with fecaliths. This excluded abscesses and local peritonitis from the definition because the latter conditions were surprisingly associated with a lower rate of post-operative complications than the former $(14 \%$ vs $18 \%$, respectively) [8].

Another issue to resolve was the definition of localized peritonitis. We thus performed a study to evaluate how surgeons define localized and generalized peritonitis. In this study, we found that the best cut-off to distinguish localized from generalized peritonitis for surgeons was two quadrants. We also found that the overall concordance between surgeons and the initial operative report was $85 \%$ [10].

We also questioned the methodology and use of a placebo in the control group. This was requested by the national fund to limit the bias of the study. However, this increased the complexity of the protocol, as antibiotics and placebo must be prepared at the pharmacy for each patient and blinded from the patient and the surgeons. We first established that nurses should also be blinded. However, it was not feasible, as nurses are reluctant to inject medications prepared by another nurse.

In conclusion, the interest of post-operative antibiotic therapy in CAA is unknown. Therefore, the present trial is designed to evaluate whether a strategy with no postoperative antibiotics is not inferior to a strategy with post-operative antibiotic therapy on organ/space SSIs by POD 30.

\section{Acknowledgements}

D. Lignier, E. Chive, A. Boussault, C. Picard.

\section{Authors' contributions}

CS and JMR: design of the study, writing of the protocol. NS: writing of the protocol. HD, JLS, and SB: design of the study. MD: statistician. The author(s) read and approved the final manuscript.

\section{Funding}

The study is funded by a Programme Hospitalier de Recherche Clinique (PHRC 2016), with a budget of $€ 960,000$. This funding source reviewed the protocol and selected it for national funding among a very limited number of selected studies. The funding source has no role in the design of the study, nor collection, analysis, or interpretation of data or writing of the manuscript.

\section{Availability of data and materials}

Data sharing is not applicable to this article as no datasets were generated or analyzed during the current study.

\section{Ethics approval and consent to participate}

Ethics approval was obtained by the Comité de Protection des Personnes (CPP, Committee for the Protection of People) on November 8, 2017 (NP1200170002) and by the Agence National de Sécurité de Médicament (ANSM, National Agency of Security of the Medication) on March 15, 2018 ( $N^{\circ}$ MEDAECNAT2018-01-00033). 


\section{Consent for publication}

Not applicable.

\section{Competing interests}

There are no competing interests.

\section{Author details}

1Department of Digestive Surgery, Amiens University Hospital, Amiens University Medical Center, Avenue Laennec, F-80054 Amiens cedex 01, France. ${ }^{2} J u l e s$ Verne University of Picardie, Amiens, France. ${ }^{3}$ SSPC (Simplifications des Soins Patients Chirurgicaux Complexes) Research Unit, University of Picardie Jules Verne, Amiens, France. ${ }^{4}$ Intensive Care Unit, Amiens University Medical Center, Amiens, France. ${ }^{5}$ Department of Methodology, Biostatistics, Direction of Clinical Research, Amiens University Medical Center, Amiens, France. ${ }^{6}$ Department of Infectious Diseases, Amiens University Medical Center, Amiens, France. ${ }^{7}$ Department of Pharmacology, Amiens University Medical Center, Amiens, France.

Received: 24 November 2019 Accepted: 14 May 2020

Published online: 01 June 2020

\section{References}

1. Addiss DG, Shaffer N, Fowler BS, Tauxe RV. The epidemiology of appendicitis and appendectomy in the United States. Am J Epidemiol. 1990; 132:910-25.

2. Sartelli M, Baiocchi GL, Di Saverio S, et al. Prospective Observational Study on acute Appendicitis Worldwide (POSAW). World J Emerg Surg. 2018;13:19.

3. Collaborative S, Cuschieri J, Florence M, et al. Negative appendectomy and imaging accuracy in the Washington State Surgical Care and Outcomes Assessment Program. Ann Surg. 2008;248:557-63.

4. Jackson HT, Mongodin EF, Davenport KP, Fraser CM, Sandler AD, Zeichner SL. Culture-independent evaluation of the appendix and rectum microbiomes in children with and without appendicitis. PLoS One. 2014;9:e95414.

5. Sabbagh C, Brehant O, Dupont H, Browet F, Pequignot A, Regimbeau JM. The feasibility of short-stay laparoscopic appendectomy for acute appendicitis: a prospective cohort study. Surg Endosc. 2012:26:2630-8.

6. Livingston EH, Woodward WA, Sarosi GA, Haley RW. Disconnect between incidence of nonperforated and perforated appendicitis: implications for pathophysiology and management. Ann Surg. 2007;245:886-92.

7. Grelpois G, Sabbagh C, Cosse C, et al. Management of uncomplicated acute appendicitis as day case surgery: feasibility and a critical analysis of exclusion criteria and treatment failure. J Am Coll Surg. 2016;223:694-703.

8. St Peter SD, Sharp SW, Holcomb GW 3rd, Ostlie DJ. An evidence-based definition for perforated appendicitis derived from a prospective randomized trial. J Pediatr Surg. 2008:43:2242-5.

9. Lefrancois $M$, Lefevre $\mathrm{JH}$, Chafai $\mathrm{N}$, et al. Management of acute appendicitis in ambulatory surgery: is it possible? How to select patients? Ann Surg. 2015;261:1167-72.

10. Mariage M, Sabbagh C, Grelpois G, Prevot F, Darmon I, Regimbeau JM. Surgeon's definition of complicated appendicitis: a prospective video survey study. Euroasian J Hepatogastroenterol. 2019;9(1):1-4.

11. Sabbagh C, Masseline L, Grelpois G, Ntouba A, Dembinski J, Regimbeau JM. Management of uncomplicated acute appendicitis as day case surgery: can outcomes of a prospective study be reproduced in real life? J Am Coll Surg. 2019;229(3):277-85.

12. Montravers $\mathrm{P}$, Dupont $\mathrm{H}$, Leone $\mathrm{M}$, et al. Guidelines for management of intra-abdominal infections. Anaesth Crit Care Pain Med. 2015;34:117-30.

13. Solomkin JS, Mazuski JE, Bradley JS, et al. Diagnosis and management of complicated intra-abdominal infection in adults and children: guidelines by the Surgical Infection Society and the Infectious Diseases Society of America. Clin Infect Dis. 2010;50:133-64.

14. Salminen P, Paajanen $H$, Rautio $T$, et al. Antibiotic therapy vs appendectomy for treatment of uncomplicated acute appendicitis: the APPAC randomized clinical trial. JAMA. 2015:313:2340-8.

15. Andersen BR, Kallehave FL, Andersen HK. Antibiotics versus placebo for prevention of postoperative infection after appendicectomy. Cochrane Database Syst Rev. 2005;20:CD001439.

16. van Rossem CC, Schreinemacher MH, Treskes K, van Hogezand RM, van Geloven AA. Duration of antibiotic treatment after appendicectomy for acute complicated appendicitis. Br J Surg. 2014;101:715-9.
17. van Rossem CC, Schreinemacher MH, van Geloven AA, Bemelman WA, Snapshot Appendicitis Collaborative Study G. Antibiotic duration after laparoscopic appendectomy for acute complicated appendicitis. JAMA Surg. 2016:151:323-9.

18. Frazee RC, Bohannon WT. Laparoscopic appendectomy for complicated appendicitis. Arch Surg. 1996;131:509-11 discussion 11-3.

19. Ball CG, Kortbeek JB, Kirkpatrick AW, Mitchell P. Laparoscopic appendectomy for complicated appendicitis: an evaluation of postoperative factors. Surg Endosc. 2004;18:969-73.

20. Pokala N, Sadhasivam S, Kiran RP, Parithivel V. Complicated appendicitis--is the laparoscopic approach appropriate? A comparative study with the open approach: outcome in a community hospital setting. Am Surg. 2007;73:73741 discussion 41-2.

21. Tuggle KR, Ortega G, Bolorunduro OB, et al. Laparoscopic versus open appendectomy in complicated appendicitis: a review of the NSQIP database. J Surg Res. 2010;163:225-8.

22. Montravers $P$, Lepape A, Dubreuil L, et al. Clinical and microbiological profiles of community-acquired and nosocomial intra-abdominal infections: results of the French prospective, observational EBIIA study. J Antimicrob Chemother. 2009:63:785-94.

23. Mangram AJ, Horan TC, Pearson ML, Silver LC, Jarvis WR. Guideline for prevention of surgical site infection, 1999. Centers for Disease Control and Prevention (CDC) Hospital Infection Control Practices Advisory Committee. Am J Infect Control. 1999;27:97-132 quiz 3-4; discussion 96.

24. Montgomery RS, Wilson SE. Intraabdominal abscesses: image-guided diagnosis and therapy. Clin Infect Dis. 1996;23:28-36.

25. Dindo D, Demartines N, Clavien PA. Classification of surgical complications: a new proposal with evaluation in a cohort of 6336 patients and results of a survey. Ann Surg. 2004;240:205-13.

26. Slankamenac K, Nederlof N, Pessaux P, et al. The comprehensive complication index: a novel and more sensitive endpoint for assessing outcome and reducing sample size in randomized controlled trials. Ann Surg. 2014;260:757-62 discussion 62-3.

27. Regimbeau JM, Fuks D, Pautrat $K$, et al. Effect of postoperative antibiotic administration on postoperative infection following cholecystectomy for acute calculous cholecystitis: a randomized clinical trial. JAMA. 2014;312: $145-54$.

28. Llor C, Bjerrum L. Antimicrobial resistance: risk associated with antibiotic overuse and initiatives to reduce the problem. Ther Adv Drug Saf. 2014;5: 229-41.

29. La Regina D, Di Giuseppe M, Cafarotti S, et al. Antibiotic administration after cholecystectomy for acute mild-moderate cholecystitis: a PRISMA-compliant meta-analysis. Surg Endosc. 2019;33:377-83.

\section{Publisher's Note}

Springer Nature remains neutral with regard to jurisdictional claims in published maps and institutional affiliations.

Ready to submit your research? Choose BMC and benefit from:

- fast, convenient online submission

- thorough peer review by experienced researchers in your field

- rapid publication on acceptance

- support for research data, including large and complex data types

- gold Open Access which fosters wider collaboration and increased citations

- maximum visibility for your research: over $100 \mathrm{M}$ website views per year

At $\mathrm{BMC}$, research is always in progress.

Learn more biomedcentral.com/submissions 